\title{
Dose related effects of oral clonidine pre-medication on bupivacaine spinal anaesthesia
}

\author{
MB Adegboye, IK Kolawole, BO Bolaji
}

Department of Anaesthesia, Faculty of Clinical Sciences, College of Health Sciences, University of Ilorin/ University of Ilorin Teaching Hospital,Ilorin, Nigeria.

\begin{abstract}
Introduction: The duration of action of sub-arachnoid block is short, and one of the ways to overcome this is the use of oral clonidine.

Methods: 108 patients of ASA I and II, aged 18 to 65 years undergoing lower abdominal surgeries under spinal anaesthesia were randomized into three groups.. Control group A $(n=36)$ no oral clonidine pre-medication, Group B ( $n=36)$ and group C $(\mathrm{n}=36)$ received $100 \mu \mathrm{g}$ and $200 \mu \mathrm{g}$ of oral clonidine pre-medication respectively, $1 \mathrm{hr}$ before spinal anaesthesia. Haemodynamic parameters were recorded. Sensory block, degree of motor blockage, and sedation were assessed.

Results: Clonidine prolonged the mean duration of motor block by $189.98 \pm 26.93 \mathrm{~min}(100 \mu \mathrm{g})$ and $191.89 \pm 28.13 \mathrm{~min}(200 \mu \mathrm{g})$ compared to $117.92 \pm 25.13 \mathrm{~min}$ in the control group $\mathrm{p}<0.05$. The mean duration of analgesia was $188.19 \pm 35 \mathrm{~min}(100 \mu \mathrm{g})$ and $194 \pm 24.58 \mathrm{~min}(200 \mu \mathrm{g})$ in the clonidine groups compared to $115.89 \pm 26.66 \mathrm{~min}$ in control group $\mathrm{p}<0.05$. All the patients were awake in the control group while $71.43 \%$ and $100 \%$ were drowsy in groups B and C respectively.

Conclusion: Oral clonidine produces better clinical effects on the onset and duration of Bupivacaine spinal anaesthesia.

Keywords: Spinal anaesthesia, pre-medication, clonidine, duration of action.

DOI: https://dx.doi.org/10.4314/ahs.v18i4.49

Cite as: Adegboye MB, Kolawole IK, Bolaji BO. Dose related effects of oral clonidine pre-medication on bupivacaine spinal anaesthesia. Afri Health Sci. 2018;18(4): 1283-1291. bttps://dx.doi.org/10.4314/abs.v18i4.49
\end{abstract}

\section{Introduction}

Regional anaesthesia, particularly spinal anaesthesia is a popular anaesthetic technique because of its simplicity, efficacy and safety. Edomwonyi et al reported that neuraxial block for prostatectomy gained overwhelming popularity in their institution ${ }^{1}$. However one of the problems of single shot spinal anaesthesia remains the limited duration of anaesthesia, even with the use of bupivacaine which is a long acting local anaesthetic agent. Various methods

\section{Corresponding author:}

MB Adegboye,

Department of Anaesthesia, Faculty of Clinical Sciences, College of Health

Sciences, University of Ilorin/ University of

Ilorin Teaching Hospital, Ilorin, Nigeria

Tel: 08030681607

E-mail: jidodedoc2000@yahoo.com have been used to prolong the duration of action of local anaesthetics when used for sub-arachnoid block.

Such methods include the addition of drugs like ketamine, magnesium sulphate, neostigmine, clonidine and opioids to local anaesthetic agents ${ }^{2}$.

Alpha-adrenergic mechanism of analgesia has been exploited for more than 100years ${ }^{3}$. Alpha ${ }^{2}$ adrenergic agonists are routinely used in the treatment of hypertension as they reduce central sympathetic outflow and modulate pre-synaptic transmitter release ${ }^{3}$. They also have hypnotic effects ${ }^{4}$. Alpha ${ }^{2}$-adenoceptors are located on primary afferent terminals (both at the peripheral and spinal endings). Neurons in the superficial laminae of the spinal cord and within several brainstem nuclei have been implicated in analgesia ${ }^{4}$.

Clonidine , an $\alpha^{2}$ adrenergic agonist produces analgesia in humans at spinal and supra-spinal sites of action ${ }^{5,6}$. The drug has been demonstrated to inhibit neurotransmission of both A delta and $\mathrm{C}$ nervefibers which mediate pin- 
prick, surgical pain, and tourniquet pain ${ }^{7,8}$. Gaumann et al have shown that clonidine enhances the effect of lidocaine on C-fibers action potential ${ }^{9}$.

Clonidine can be administered systemically, epidurally and intrathecally. Oral administration of clonidine results in virtually complete absorption and peak plasma concentration occurs 1-3 hours after administration ${ }^{5}$. The drug is highly lipid soluble easily crosses the blood-brain barrier and therefore may interact with $\alpha$-adrenergic receptors at spinal and supraspinal sites within the central nervous system $^{10}$. Several studies have been done to evaluate the effects of oral clonidine when used as a pre-medicant before administering spinal anaesthesia ${ }^{3,11,12,13,14}$.

The aim of this study was to evaluate if a dose-related effect exists when two different doses of oral clonidine are administered as a pre-medicant in the enhancement of bupivacaine spinal anaesthesia, to compare the haemodynamic effects of such doses and to evaluate the sedative effect of oral clonidine.

\section{Material and methods}

The prospective randomized, double blind controlled study was approved by institution ethical review committee and consisted of 108 consenting ASA I and II patients who were randomized into three groups. Patients with bleeding disorders, neurological disorders, previous history of adverse reaction to bupivacaine and clonidine, and, patients on anti-hypertensive therapy were excluded from the study. After detailed examination, the patients between ages 18 and 65 years undergoing lower abdominal or lower limbs surgeries under spinal anaesthesia were assigned into three groups.

The control group A $(n=36)$ had no clonidine pre-medication while groups $B(n=36)$ and $C(n=36)$ received 100 $\mu \mathrm{g}$ and $200 \mu \mathrm{g}$ of oral clonidine one hour before spinal anaesthesia respectively.

Using a multiparameter patient monitor, the heart rate (HR), systolic blood pressure (SBP), diastolic blood pressure (DBP), mean arterial pressure (MAP) and arterial oxygen saturation were measured non-invasively. The parameters were recorded before pre-medication with oral clonidine, at the time spinal anaesthesia was given (zero minute) and at 30 min after anaesthesia.

Sedation score was assessed using a four point scale (1=Awake, 2 =Drowsy but responsive to verbal stimulus,
$3=$ Drowsy but arousable to touch, $4=$ unarousable $^{5}$. An intravenous line was secured using a 16-gauge cannula and each patient was pre-loaded with $15 \mathrm{ml} / \mathrm{kg}$ of normal saline over 20 minutes. Patients were then placed in the sitting position. Using aseptic technique, skin infiltration was done using 1\% lidocaine and lumbar puncture was performed using a $25 \mathrm{G}$ Whitacre spinal needle at L2/L3 or L3/L4 intervertebral space. Once free flow of cerebrospinal fluid was obtained, $15 \mathrm{mg}$ of $0.5 \%$ heavy bupivacaine (Myungmoon Pharm. Co, LTD), was injected. Haemodynamic parameters were monitored every 2 min initially for the first ten minutes, then every $5 \mathrm{~min}$ until end of surgery. Hypotension was defined as reduction in systolic blood pressure by $25 \%$ below pre-anaesthetic value or decreased systolic pressure below $90 \mathrm{mmHg}$ and was noted if it occurred and treated with rapid infusion of normal saline, oxygen administration, and ephedrine in $3 \mathrm{mg}$ bolus doses titrated to effect. Heart rates less than 50 beats per min were treated with titrated doses of atropine $0.6 \mathrm{mg}$ as required.

The level of sensory anaesthesia was assessed in the midclavicular line bilaterally using loss of sensation to pinprick with a $21 \mathrm{G}$ needle. Response to pinprick was studied every 5 minutes for 30 minutes after the injection of the local anaesthetic. Onset of anaesthesia was considered as appearance of sensory block at L1. The degree of motor block was assessed at 2 minutes and then at 5 minutes interval for 20 minutes, using a modified Bromage scale $(0=$ no motor block, $1=$ inability to raise the extended legs, $2=$ inability to flex the knees, $3=$ inability to flex the ankle joints). Assessment was not carried out during surgery but was continued after surgery, every 30 minutes until full recovery. The duration of analgesia was considered as time between onset and time when sensory level weaned off to L1.

Post-operatively in the recovery room the total duration of sensory and motor block was noted.

Haemodynamicaly stable patients with sensory level lower than L1 and ability to lift both lower limbs were discharged to the ward.

\section{Data analysis}

The data generated were presented as means and standard deviations, proportions and percentages as appropriate. 
Statistical analyses were done using computer software package Excel 2007 version. Means were compared using Student's t-test for 2 groups or ANOVA for 3 groups. Categorical data were compared with Chi-square test. P value $\leq 0.05$ was considered statistically significant.

\section{Results}

All the patients in the three groups had comparable demographic characteristics (Table 1).

Table II show the haemodynamic variables at rest, before oral clonidine was administered, at zero minute, that is, before spinal anaesthesia was given and at thirty minutes after spinal anaesthesia. There were no significant differences in the variables between the three groups at rest before oral clonidine was given. The mean HR at zero minute was lower in the clonidine groups than the control group but this was only statistically significant when the control group was compared with the $200 \mu \mathrm{g}$ clonidine group $(\mathrm{p}=0.05)$.

The table also shows haemodynamic measurements thirty minutes after spinal anaesthesia. The mean HR in group B $(100 \mu \mathrm{g})$ and group C $(200 \mu \mathrm{g})$ were significantly lower than the control group, $\mathrm{p}=0.05$ and $\mathrm{p}=0.024$ respectively (Table III). There was no difference in the mean HR between the clonidine groups $\mathrm{p}=0.307$ (Table III).

Table I: Demographic characteristics of surgical patients given oral clonidine

\begin{tabular}{lclllll}
\hline & N & Male: female & Age (year) & WT (Kg) & Ht(m) & ASA I/II \\
\hline Group A & 36 & $10: 26$ & $40.27 \pm 14.51$ & $71.27 \pm 17.63$ & $1.64 \pm 0.09$ & $23 / 13$ \\
Group B & 36 & $20: 16$ & $41.75 \pm 10.89$ & $77.83 \pm 20.43$ & $1.53 \pm 0.18$ & $26 / 10$ \\
Group C & 36 & $22: 14$ & $40.52 \pm 13.05$ & $63.61 \pm 8.9$ & $1.62 \pm 0.09$ & $14 / 22$ \\
P value & & & $\mathbf{1 . 1 6 1}$ & $\mathbf{0 . 9 0 0}$ & $\mathbf{0 . 9 0 0}$ &
\end{tabular}

Values are mean \pm SD

No significant differences among groups 
Table II: Heamodynamic parameters of patients at rest (baseline), zero minute before instituting spinal and $\mathbf{3 0}$ minutes after spinal anaesthesia.

\begin{tabular}{lllll}
\hline & & At rest & Before spinal & $30 \mathrm{~min}$ \\
\hline HR & A & & & \\
& B & $82.5 \pm 15.6$ & $97.5 \pm 22.7$ & $92 \pm 19.8$ \\
& C & $87.1 \pm 88$ & $96.6 \pm 8.8$ & $83.9 \pm 19.9$ \\
& P value & $91.9 \pm 19.8$ & $87.0 \pm 12$ & $84.6 \pm 13.7$ \\
SBP & A & 1.801 & 0.164 & 0.044 \\
& B & $135 \pm 6.7$ & $136.7 \pm 17.7$ & $126.4 \pm 17.2$ \\
& C & $139.1 \pm 17.1$ & $148.3 \pm 22.2$ & $130.1 \pm 11.6$ \\
& P value & $121.5 \pm 11.6$ & $120.3 \pm 10$ & $106.8 \pm 8.8$ \\
DBP & A & 0.258 & 0.584 & 0.065 \\
& B & $76.8 \pm 14.5$ & $76.8 \pm 14.5$ & $70.5 \pm 148$ \\
& C & $81 \pm 11$ & $81 \pm 11$ & $72.1 \pm 12$ \\
P value & $70.6 \pm 8.3$ & $70.6 \pm 8.3$ & $62.3 \pm 8.7$ \\
MAP A & 0.760 & 0.760 & 0.352 \\
& B & $98.4 \pm 13.5$ & $98.8 \pm 14.4$ & $92.3 \pm 15.1$ \\
C & $106.3 \pm 31.4$ & $105.3 \pm 14.8$ & $93.4 \pm 10.7$ \\
P value & $90.7 \pm 7.6$ & $89.6 \pm 9.6$ & $78.7 \pm 8$ \\
\hline
\end{tabular}

$\mathrm{N}=36$ patients in each group

GROUP A $=$ No clonidine

GROUP B $=100 \mu \mathrm{g}$

GROUP C $=200 \mu \mathrm{g}$

The mean SBP, DBP and MAP of the patients in group C $(200 \mu \mathrm{g})$ group were significantly lower than those of the control group $\mathrm{p}=0.000,0.001$ and 0.000 respectively $(\mathrm{Ta}$ ble III). The SBP, DBP and MAP of the $200 \mu \mathrm{g}$ clonidine were also significantly lower than those of the group $\mathrm{B}$ $(100 \mu \mathrm{g}) \mathrm{p}=0.000$ for each variable (Table III).

Table IV shows the absolute degree of change of the haemodynamic parameters of all the groups from the baseline. In the control group A the mean HR significantly increased from the baseline $(p=0.01)$, the mean SBP was significantly reduced from the baseline $(p=0.028)$ while the change in the parameters of mean DBP and MAP from the baseline were not statistically significant $(\mathrm{p}=1.101$ and 0.103 respectively).

The absolute degree of haemodynamic changes of group

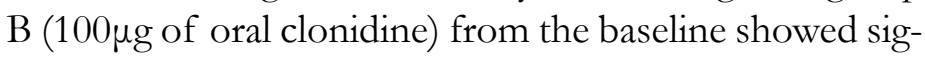
nificant reductions in the mean $\mathrm{HR}(\mathrm{p}=0.000), \mathrm{SBP}(\mathrm{p}=$ $0.000), \operatorname{DBP}(\mathrm{p}=0.003)$ and MAP $(\mathrm{p}=0.017)$.

The $200 \mu \mathrm{g}$ oral clonidine group (group $\mathrm{C}$ ) showed significant reductions in SBP, DBP and MAP at 30 minutes ( $p=0.000$ respectively) as shown in Table IV. However there was no statistically significant reduction in mean $\mathrm{HR}(\mathrm{p}=0.133)$ 
Table III: Comparing P values of haemodynamic parameters of groups at rest, before spinal (zero minutes) and $\mathbf{3 0}$ minutes.

\begin{tabular}{llccl}
\hline & & P value at rest & P value before spinal & P value 30 min \\
\hline HR & A vs B & 0.077 & 0.809 & 0.005 \\
& B vs C & 0.001 & 0.000 & 0.307 \\
& A vs C & 0.000 & 0.005 & 0.024 \\
SBP & A vs B & 0.146 & 0.000 & 0.196 \\
& B vs C & 0.000 & 0.000 & 0.000 \\
& A vs C & 0.000 & 0.000 & 0.000 \\
DBP & A vs B & 0.000 & 0.000 & 0.513 \\
& B vs C & 0.158 & 0.000 & 0.000 \\
& A vs C & 0.259 & 0.009 & 0.001 \\
MAP & A vs B & & & \\
& B vs C & 0.000 & 0.006 & 0.667 \\
A vs C & 0.002 & 0.000 & 0.000 \\
\hline
\end{tabular}

Table IV: Haemodynamic changes of the groups from baseline to $\mathbf{3 0}$ minutes after spinal anaesthesia

\begin{tabular}{cccccc}
\hline & & Baseline & 30 min & \% change & P value \\
\hline A & HR & $82.5 \pm 8.8$ & $92 \pm 19.7$ & 11.48 & 0.010 \\
& SBP & $135.1 \pm 16.7$ & $126.4 \pm 17.2$ & 6.40 & 0.028 \\
& DBP & $75.9 \pm 10.3$ & $70.5 \pm 14.8$ & 7.03 & 1.101 \\
& MAP & $98.4 \pm 13.5$ & $92.3 \pm 15.1$ & 6.13 & 0.103 \\
& & & & \\
B & HR & $87.1 \pm 8.8$ & $83.9 \pm 13.7$ & 4.95 & 0.000 \\
& SBP & $139.1 \pm 17.1$ & $130.1 \pm 11.6$ & 6.47 & 0.000 \\
& DBP & $76.1 \pm 9.6$ & $72.1 \pm 12$ & 5.36 & 0.003 \\
& MAP & $106.3 \pm 31.4$ & $93.4 \pm 10.7$ & 12.10 & 0.017 \\
& & & & & 0.133 \\
C & HR & $91.9 \pm 19.8$ & $84.6 \pm 13.7$ & 7.97 & 0.000 \\
& SBP & $121.5 \pm 11.6$ & $106.8 \pm 8.8$ & 12.02 & 0.000 \\
& DBP & $73.9 \pm 8$ & $62.3 \pm 8.7$ & 15.07 & 0.000
\end{tabular}

\section{Onset of Sensory Block (Table V)}

The onset of sensory block was significantly faster in the clonidine groups than the control group, It was 6.69 \pm 2.55 mins in the control group compared to $2.19 \pm 0.7$ mins in the $100 \mu \mathrm{g}$ clonidine group $(\mathrm{p}=0.000)$ and 2.08 \pm 0.28 mins in the $200 \mu$ g group $(p=0.000)$. There was no significant difference in onset of sensory block between the clonidine groups $(p=0.348)$

\section{Onset of Motor Block (Table V)}

The onset of motor block was significantly faster in the clonidine groups than the control group.

It was $2.05 \pm 0.41 \mathrm{mins}$ in the control group compared to $1.02 \pm 0.16$ mins in the $100 \mu \mathrm{g}$ clonidine group $(\mathrm{p}=0.000)$ and $1.00 \pm 0.00 \mathrm{mins}$ in the $200 \mu \mathrm{g}$ group $(\mathrm{p}=0.0000)$. There was no significant difference in onset of motor block between the clonidine groups $(p=0.317)$. 


\section{Table V: Comparison of Onset of Sensory and Motor Block amongst the Groups (Mean \pm SD)}

\begin{tabular}{lll}
\hline Groups & Sensory Block (mins) & Motor Block (mins) \\
\hline Group A & $6.69 \pm 2.55$ & $2.05 \pm 0.41$ \\
Group B & $2.19 \pm 0.7$ & $1.02 \pm 0.16$ \\
Group C & $2.08 \pm 0.28$ & $1.0 \pm 0.0$ \\
\hline
\end{tabular}

Sensory block $p$ value GROUP A vs B GROUP A vs C GROUP B vs $C$

Motor block $p$ value

0.000

0.000

0.348
0.000

0.000

0.317

\section{Duration of Sensory Block (Table VI )}

The duration of sensory block was significantly longer in the clonidine groups than the control group. It was 115.89 $\pm 26.66 \mathrm{mins}$ in the control group compared to 188.19 $\pm 35.19 \mathrm{mins}$ in the $100 \mu \mathrm{g}$ clonidine group $(\mathrm{p}=0.000)$ and $194 \pm 24.58 \mathrm{mins}$ in the $200 \mu \mathrm{g}$ group $(\mathrm{p}=0.000)$. There was no significant difference in duration of sensory block between the two clonidine groups $(\mathrm{p}=0.138)$.

\section{Duration of Motor Block (Table VI)}

The duration of motor block was also significantly longer in the clonidine groups than the control group. It was $117.92 \pm 25.13$ mins in the control group compared to $189.94 \pm 26.93$ mins in the $100 \mu \mathrm{g}$ clonidine group ( $\mathrm{p}=$ $0.000)$ and $191.89 \pm 28.13$ mins in the $200 \mu \mathrm{g}$ clonidine group $(p=0.000)$. There was no difference in duration of motorblock between the two clonidine groups $(\mathrm{p}=$ $0.678)$.

\section{Table VI: Comparison of Duration of Sensory and Motor Block amongst the groups (Mean \pm SD)}

\begin{tabular}{llc}
\hline GROUPS & Sensory Block(Mins) & Motor Block (Mins) \\
\hline Group A & $115.89 \pm 25.66$ & $117.92 \pm 25.13$ \\
Group B & $188.19 \pm 35.19$ & $189.94 \pm 26.93$ \\
Group C & $194.28 \pm 24.58$ & $191.89 \pm 28.13$ \\
\hline
\end{tabular}

\begin{tabular}{lll} 
Sensory block $p$ value & \multicolumn{2}{c}{ Motor block $p$ value } \\
GROUP A vs B & 0.000 & 0.000 \\
GROUP A vs C & 0.000 & 0.000 \\
GROUP B vs C & 0.138 & 0.678
\end{tabular}

\section{Sedation Score}

Sedation score showed that the patients in the clonidine groups were more sedated than those in the control group. All the patients (100\%) in the control group were awake, while in the $100 \mu \mathrm{g}$ clonidine group $28.57 \%$ were awake and $71.43 \%$ were drowsy but responded to verbal stimulation. In the $200 \mu \mathrm{g}$ clonidine group, all the patients i.e. $100 \%$ were drowsy but responded to verbal stimulus (Table VII). 
Table VII: Degree of Sedation among the Groups

\begin{tabular}{lllll}
\hline GROUP & $1(\%)$ & $2(\%)$ & $3(\%)$ & $4(\%)$ \\
\hline GROUP A & 100 & 0 & 0 & 0 \\
GROUP B & 28.57 & 71.43 & 0 & 0 \\
GROUP C & 0 & 100 & 0 & 0 \\
\hline
\end{tabular}

$\begin{array}{ll}\text { 1: } & \text { Awake } \\ \text { 2: } & \text { Drowsy but responsive to verbal stimulus } \\ \text { 3: } & \text { Drowsy but arousable to touch } \\ \text { 4: } & \text { Unarousable }\end{array}$

\section{Discussion}

The study showed that patients pre-medicated with $100 \mu \mathrm{g}$ clonidine had a $4.95 \%$ fall in heart rate at thirty minutes when compared to the base line, which was statistically significant $(\mathrm{p}=0.000)$. Group C $(200 \mu \mathrm{g})$ also had a $7.95 \%$ fall in heart rate at thirty minutes when compared to the baseline $(p=0.133)$, while the control group had an increase in heart rate of $11.48 \%$ from the baseline when compared to thirty minutes which was statistically significant $(p=0.010)$. The increase in heart rate in the control group was probably due to the lack of the net effects of clonidine which is to down-regulate, or at least reduce the sympathetic response. The result of the heart rate at zero minute and thirty minutes in group B $(100 \mu \mathrm{g})$ was similar to studies conducted by Swati et $\mathrm{a}^{15}$. Liu et al also reported a significant fall in heart rate in patients pre-medicated with $200 \mu \mathrm{g}$ of oral clonidine ${ }^{5}$. All the groups had a statistically significant fall in systolic blood pressure from the baseline, group A $(6.40 \%)$, group B $(6.47 \%)$ and group $\mathrm{C}(12.02 \%)$ probably due to the additive effects of spinal anaesthesia. These findings were similar to the study by Liu et $\mathrm{al}^{2}$. Group B $(100 \mu \mathrm{g})$ and group C $(200 \mu \mathrm{g})$ of oral clonidine had significant decrease in DBP and MAP, from the baseline $(p<0.05)$. This decrease was not seen in the control group A ( $>>0.05)$.

Various studies have shown that oral clonidine, when used as pre-medication before spinal anaesthesia has effects on the duration of sensory and motor block ${ }^{3,5,15,16}$. In the study by Swati et $\mathrm{al}^{15}$ the duration was prolonged by 30 40 minutes. In all the previous studies mentioned above, a single dose of clonidine was used but in our study two different doses of clonidine were used and the aim was to establish if there was a dose related effect on the onset and duration of sensory and motor block.

The onset of sensory block at L1 was faster in the clonidine groups when compared with the control group. ( TableV). This was comparable with the study of Aftab et $\mathrm{al}^{3}$.However, when the clonidine groups were compared, the difference in time of onset at L1 was not statistically significant $p>0.05$. Similarly the onset of motor block was faster in the clonidine groups than the control group (Table V). This result was different from that of Afteb et al who reported that the onset of motor block was similar between the control group and patients pre-medicated with $150 \mu \mathrm{g}$ of oral clonidine ${ }^{3}$.

Liu et $\mathrm{al}^{5}$ and Harbhej et $\mathrm{al}^{17}$ also found that $200 \mu \mathrm{g}$ of oral clonidine prolonged the duration of lignocaine and tetracaine spinal anaesthesia respectively. The study of Otalet $\mathrm{al}^{12}$ compared the dose-related effects using three different doses of oral clonidine $75 \mu \mathrm{g}, 150 \mu \mathrm{g}$ and $300 \mu \mathrm{g}$ on tetracaine spinal anaesthesia. The dose response data suggested that the prolongation of sensory block by oral clonidine seems to plateau at a dose of $150 \mu \mathrm{g}$ because regression to L1 dermatome was increased by $45 \%$ with $75 \mu \mathrm{g}, 92 \%$ with $150 \mu \mathrm{g}$ and $76 \%$ with $300 \mu \mathrm{g}$ of oral clonidine respectively. In this study, the result of the comparison of the sensory and motor blocks of the control group to the clonidine groups is similar to other studies mentioned above $5,12,17$. The result shows a statistical significant increase in duration of sensory and motor blocks in the clonidine groups when compared to the control group $(p<0.05)$. Interestingly, there were no differences in the duration of sensory and motor blocks between the two clonidine groups in this study. Comparing these re- 
sults with those of Ota et $\mathrm{al}^{12}$, who concluded that the effect of oral clonidine on duration of tetracaine spinal anaesthesia seems to plateau at $150 \mu \mathrm{g}$, this study shows that the effect of oral clonidine on duration of sensory and motor block in bupivacaine spinal anaesthesia is in

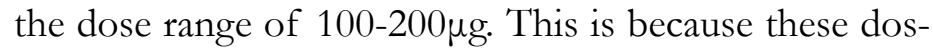
ages prolonged sensory and motor blocks almost equally. The mechanisms of how oral clonidine affects sensory and motor block remains unclear, however direct inhibition of $\mathrm{A}$ alpha motor fibers, $\mathrm{C}$ nerve fibers ${ }^{8}$ and augmentation of intrathecal local anaesthetic effects ${ }^{19}$ has been postulated to play a role in the effects of oral clonidine.

Butterworth and Strichartz ${ }^{8}$ demonstrated that analgesia after neuraxial administration of $\alpha_{2}$-adrenergic agonists may, in fact, result from direct inhibition of impulse conduction in the $A \alpha$ and $C$ fibers. However unlike the traditional local anaesthetics, clonidine produces greater inhibition of $\mathrm{C}$ fibers than $\mathrm{A} \alpha$ fibers ${ }^{20}$. Some of the analgesic efficacy of $\alpha_{2}$-adrenergic agonists following regional injection may result from a local anaesthetic -type of action on $\mathrm{A} \alpha$ and, especially, $\mathrm{C}$ fibers. In this study the duration of analgesia in the control group was $115.89 \pm 26.66 \mathrm{~min}$ while that of the clonidine groups were 188.14 \pm 35.19 $\min (100 \mu \mathrm{g})$ and $194 \pm 24.58 \mathrm{~min}(200 \mu \mathrm{g})$ respectively which was statistically significant $\mathrm{p}=0.00$ this was similar to that of several studies ${ }^{3,14,15}$. The potent analgesic property of clonidine is because it acts at spinal and supraspinal sites, it has a non-opioid mechanism of analgesic action on the medullospinal noradrenergic pathway modulating spinal nociceptive processing and the $\alpha_{2}$-adrenergic receptor that are strategically located on the dorsal horn neurons of the spinal cord where it can either inhibit the release of nociceptive neurotransmitters such as substance 'P' or calcitonin gene related peptide. ${ }^{14}$ Another analgesic mechanism is by the synergistic interaction between $\alpha_{2}$-adrenergic agonist and opiates in the spinal cord. ${ }^{14}$

Sedation has been shown to increase patient's satisfaction during regional anaesthesia ${ }^{21}$ and may be considered as a means to increase the patient's acceptance of regional anaesthetic techniques.

For surgery under regional anaesthesia, sedation is a valuable tool to make it more convenient for the patient, the anaesthetist, and the surgeon. In this study, the incidence of sedation with $100 \mu \mathrm{g}$ of oral clonidine was $71.43 \%$ while the control group had zero percent. This is comparable to the pattern observed in the study by Swati et al in which the incidence of sedation using $100 \mathrm{mcg}$ of oral clonidine was $64 \%$ while the control group had zero percent $^{15}$. However the incidence of sedation in the $200 \mu \mathrm{g}$ of oral clonidine was $100 \%$, suggesting that the incidence of sedation had a dose response effect. Liu et al also reported that the incidence of sedation was greater in the group premedicated $200 \mu \mathrm{g}$ of oral clonidine and was in agreement with previous dose-response studies of oral clonidine ${ }^{22,23}$. Clonidine produces a dose-dependent sedation over the dose range of $50-900 \mu \mathrm{g}$ of rapid onset (20minute) regardless of the route of administration ${ }^{4}$.

\section{Conclusion}

The study demonstrated that pre-medication of healthy patients with oral clonidine one hour prior to bupivacaine spinal anaesthesia gave a faster onset andlonger duration of spinal anaesthesia. Furthermore, it also provided a distinct advantage because of its sedative property.

\section{Recommendations}

Based on the findings in this study, it is recommended that the use of oral clonidine pre-medication before bupivacaine spinal anaesthesia in adults is desirable.

Opioids which are one of the commonest agents added to local anaesthetic to prolong its duration is not always available in tertiary health centres and hardly available in non-specialist hospitals. Therefore, we advocate the use of oral clonidine as a pre-anaesthetic medication in all healthy adult surgical patients for elective surgical procedure involving the lower abdominal and lower limbs under bupivacaine spinal anaesthesia because it prolongs spinal anaesthesia, provides desirable sedative effects and a tolerable peri-operative heamodynamic profiles.

\section{Acknowledgements}

We wish to acknowledge with thanks, the support of all the staff members of the Departments of Anaesthesia and surgery of University of Ilorin Teaching hospital in the course of this study.

\section{Source of funding}

None.

\section{Conflict of interest}

None. 


\section{References}

1. Edomwonyi N.P, Omoifo C.E Increasing use of regional anaesthesia for prostatectomy. $S A J A A$. 2008; 14:13-17. PubMed.

2. Ozalevli M, Cetin TO, Unlugenc H, Guler T, Isik.G. The effect of adding intrathecal magnesium sulphate to bupivacaine-fentanyl spinal anaesthesia. Acta Anaesth Scandinavica. 2005; 49: 1514-1519.

3. AftabBeighAkhtar N, Farooq A K. Haemodynamic and analgesic effects of oral clonidine on sub-arachnoid block with lidocaine. J Anaesthclin.Pharmacol. 2003; 19:389393. PubMed.

4. Elsenach, James C., De Kock, Marc, Klimscha, Walter. Alpha sub- Adrenergic Agonist for Regional Anaesthesia: A Clinical Review. Anesthesiology. 1996; 85: 655-674. PubMed.

5. Liu, Spencer, Andrew A., Neal, Joseph M., Randal L., et al. Oral Clonidine Prolongs Spinal Anaesthesia in Human Volunteers. Anesthesiology. 1993; 86 :1353-1359. PubMed.

6. Bonnet F, Boico O, Rostaing S, Loriferne TF, Saada $\mathrm{M}$. Clonidine-induced analgesia in post-operative patients Epidurals verus intra-muscular administration. Anesthsiology. 1990;72:423-427.

7. Wang C, Knowles MG, Chakrabarti MK, WhitwanJG. Clonidine has comparable effects of spontaneous sympathetic activity and afferent $\mathrm{A}$ delta and $\mathrm{C}$-fiber-mediated somatosympathetic reflexes. Anesthesiology. 81;1994.710717.

8. Butterworth JF, Strichartz GR., The Alpha2-adrenergic agonist clonidine and guanfacine produce tonic and phase block of conduction in rat nerve fibers. Anesth $A n$ alg. 1993; 76:295-301.

9. Gaumann OM, Brunet PC, Firolinek PB. Clonidine enhances the effects of lidocaine on Cfibers action potential. AnesthAnalgl. 1992:74:719-725. PubMed.

10. Timmermans PB, Brands A, Van Zwietan PA. Lipophilicity and brain disposition of clonidine and structurally related imidazolidines. Naunyn-Schmiedergs Arch Phamacol. 1977;300:217-226.

11. Pouttu J, Tuominen M, Scheinin M, Rosenbert PH. Effects of oral clonidine pre-medication on concentrations of cortisol and monoamine neurotransmitters and their metabolites in cerebrospinal fluid and plasma. ActaAnaesthscand. 1989;33:137-141.

12. Ota, Namiki A, Iwasaki H, Takahashi I. Dose-related prolongation of spinal anaesthesia in humans. Anesthesiology. 1995;82:1353-1359. PubMed.

13. Bonnet F, Brun Buisson V, Francois Y. Effects of oral and sub-arachnoid clonidine on spinal anaesthesia with bupivacaine. Reg Anesth. 1990;15:2

14. Sudar CR, Selyarajan N, Manimekalai K, Kartik JS. Effects of oral clonidine pre-medication on the duration of analgesia produced by spinal Bupivacaine. Int J Pham Bio Sci. 2013;4:1017-1024.

15. Swati D, Sunita G, Dixit V. Effect of Oral Clonidine Premedication on Spinal Anaesthesia using 5\% Hyperbaric Lignocaine. Bombay Hospital Journal. 2007;49:3-4 16. Azad A, Kats RL, Patel RV, etal. The effect of oral clonidine on the duration of lidocaine spinal anaesthesia. Anesthesiology. 1994;81:A944.

17. Harbhej S, Jin L, George Y,etal. Effect of oral clonidine and intrathecal fentanyl on tetracaine spinal block. Anesth Analg. 1994;79:1113-1119. PubMed.

18. Singh H, Liu J, Gains GY, White PF: Effect of oral clonidine and intrathecal fentanyl on spinal block. Anesth Analg. 1994 70:117-1120. PubMed.

19. Cosby G, Russo MA, Szabo MD, Davies KR: Subarachniod clonidine reduces spinal cord blood flow and glucose utilization in conscious rats. Anesthesiology. 1990; 73:1179-1185. PubMed.

20. Raymond SA, Gisssen AJ. Mechanism of differential nerve block In: Strichartz GR, ed. Local anaesthetics. Berlin: Springer-Verlag. 1987:95-164.

21. Wu CL, Naqibuddin M, Fleisher LA. Measurement of patient satisfaction as an outcome of regional anaesthesia and analgesia: a systematic review. Reg Anesth Pain Med. 2001; 26:196-208.

22. Filos KS, Patroni O, Goudas LC, Bosas O, et al. A dose-respose study of orally administered clonidine as pre-medication in the elderly: Evaluating heamodynamic safety. Anesth Analg. 1993;77:1185-1192.

23. Carabine UA, Wright PMC, Moore J: Preanaesthetic medication with clonidine: A dose-response study. $\mathrm{Br}$ Anesth J. 1991; 67:79-83. PubMed. 